\title{
A palavra em disputa
}

Os homens explicam tudo para mim.

SOLNIT, Rebecca.

Trad. de Isa Mara Lando.

São Paulo: Cultrix, 2017, 205 p.

Rebecca Solnit é uma jornalista, historiadora e escritora estadunidense, com diversos livros publicados sobre mudanças sociais, arte, política e feminismo. Em Os homens explicam tudo para mim, livro que reúne nove ensaios publicados por Solnit entre 2008 e 2014 em jornais e sites de notícias nos Estados Unidos, a autora se debruça sobre o tema dos direitos das mulheres para discutir, entre outras questões, a violência contra as mulheres, tão normalizada em nossa sociedade e pouco discutida como o que de fato é: um padrão persistente de uma cultura patriarcal. O enraizamento e a invisibilidade das violências de gênero são abordados pela autora em várias esferas, tratando do estupro e do assédio sexual no trabalho, da violência doméstica e dos feminicídios que são, quase sempre, cometidos por parceiros ou ex-parceiros, citando exemplos e estatísticas dos Estados Unidos e de outros países. Para Rebecca Solnit (2017, p. 17), "a violência é uma maneira de silenciar as pessoas, de negar-lhes a voz e a credibilidade, de afirmar que o direito de alguém de controlar vale mais do que o direito delas de existir, de viver". No ensaio intitulado "A guerra mais longa", os casos de estupro coletivo nos Estados Unidos e na Índia e a epidemia de estupros nos campi das universidades estadunidenses são usados para ilustrar que "a violência não tem raça, nem classe, nem religião, nem nacionalidade; mas tem gênero" (Rebecca SOLNIT, 2017, p. 35).

Se os dados apresentados pela autora sobre a violência contra as mulheres nos Estados Unidos são tão assustadores quanto os dados brasileiros e de outros países, também é possível traçar paralelos quanto a outros comportamentos, seja da imprensa, seja das instituições responsáveis por punir esses crimes no que tange à forma como analisam e interpretam esses acontecimentos. Alguns dos problemas percebidos se referem ao fato de considerar esses incidentes excepcionais ou anomalias de alguns indivíduos, em transformar o caso em um espetáculo, principalmente se envolver celebridades, sem considerar os muitos incidentes diários, que atravessam todas as classes sociais, idades, culturas, raças e regiões, o que de fato permitiria evidenciar o padrão de violência que se repete nas sociedades contemporâneas. 
A autora coloca em evidência vários casos de violência sexual, violência doméstica e assédio, demonstrando que os perpetradores são homens; no entanto, ela pondera que nem por isso todos os homens são violentos, observando que as mulheres também podem cometer violências, mas, de acordo com as estatísticas, em proporção bem menor. Com isso, a autora determina que o assunto do livro é a pandemia de violência dos homens contra as mulheres, o que transforma uma grande parcela da população feminina em sobreviventes de algum tipo de violência. Além disso, Solnit faz uma crítica importante em relação às explicações que prevalecem acerca dessas violências, pautadas nos mais diversos motivos, menos no mais necessário: as questões de gênero.

No ensaio que dá título ao livro, a autora narra uma situação já vivida por praticamente todas as mulheres: a de ter um homem explicando a ela algo que ele não sabe, sobre um assunto que ela domina. O ensaio de Solnit sobre o tema teve grande repercussão na imprensa e acabou por criar a palavra mansplaining, adotada pelo movimento feminista para referir-se à situação em que os homens assumem que são superiores apenas por serem do sexo masculino e explicam às mulheres coisas que elas já sabem. Mais que isso: Solnit observa como historicamente esse silenciamento das mulheres tem sido e ainda é construído, pois ainda não são muitas as mulheres, mesmo nos dias de hoje, que conseguem assumir sua voz e o seu conhecimento publicamente, com a confiança de um percurso de desenvolvimento percorrido.

A autora também destaca a Internet como algo extremamente significativo nessa nova onda dos feminismos que ganham força disseminando ideias e promovendo encontros e reivindicações a partir das redes sociais, mas que também as expõe a outros tipos de violências e assédios virtuais. As perseguições e ameaças sofridas por aquelas que manifestam suas opiniões publicamente na Internet e se assumem feministas é algo que tem se propagado e que intimida muitas mulheres a falar e escrever. Mais uma vez é o silenciamento da voz das mulheres o objetivo do sistema patriarcal.

Em resposta às muitas retomadas conservadoras que temos presenciado no Brasil e no mundo, a mobilização através das redes sociais, principalmente no Twitter, formou movimentos de resistência ao tornar visíveis histórias de violências há muito silenciadas e tentar abrir espaço para as vozes das mulheres. Solnit apresenta o exemplo do contexto político estadunidense e as tentativas de eliminar os direitos reprodutivos das mulheres e seu controle sobre os próprios corpos justamente para demonstrar que a violência contra as mulheres é, antes de tudo, uma questão de controle e faz críticas ao descaso nas investigações de casos de estupro no país. Como mostra a autora, ao invés de punir e educar os agressores, ainda prevalece o comportamento de preparar as mulheres para lidar ou tentar evitar/se defender dessas violências, ainda que aconteçam praticamente em todos os espaços, sejam públicos ou privados.

Com base no exemplo de uma acusação de estupro feita por uma camareira contra o diretor do Fundo Monetário Internacional, caso que ganhou grande destaque na mídia estadunidense, Solnit reflete sobre feminismo e a luta de classes, ponderando como os privilégios sociais têm impacto na forma como o processo criminal foi realizado, com promotores públicos abandonando a acusação criminal e manchando a reputação da vítima através da imprensa para deslegitimar sua denúncia, conduta comum em diversos casos, seja no Brasil ou nos Estados Unidos, em casos de estupro, pois, como observa Flávia Biroli:

A negação da realidade do estupro decorre amplamente do fato de que a validade do consentimento dos indivíduos é distintamente considerada se são homens ou mulheres - e isso se agrava quando se leva em consideração a posição de classes dessas mulheres e possíveis "desvios" em sua vida sexual em relação aos códigos morais predominantes. (Flávia BIROLI, 2014, p. 112) 
Outro tema abordado pela autora e que perpassa toda a discussão sobre feminismo e violência contra as mulheres apresentado no livro é o poder da linguagem, instrumento que ela considera fundamental na luta pelos direitos humanos e, mais ainda, na reivindicação dos direitos das mulheres. Assim, Solnit destaca a importância das palavras usadas no jornalismo e pela mídia de modo geral ao narrar casos de violência e o impacto que possuem tanto para reiterar a normalização da violência contra as mulheres, quanto para ajudar a transformar a sociedade e a visão do senso comum sobre esse problema. Alguns exemplos de letras de música que reproduzem o discurso de que as mulheres são propriedade dos homens e agredi-las é um direito deles são trazidos por Solnit para ilustrar de que modo essas representações, até mesmo na música e nas outras artes, têm impacto sobre a nossa forma de ver o mundo. As imagens da artista plástica Ana Teresa Fernandez que abrem cada um dos ensaios, por sua vez, sempre destacando figuras femininas em situações cotidianas e inusitadas, são provocações que dialogam com as reflexões da autora, em especial no ensaio "Avó aranha", exaltando o poder da arte. Nas palavras de Rebecca Solnit, após analisar um dos quadros de Ana Teresa Fernandez onde se vê uma mulher de salto alto estendendo um lençol no varal e tendo o rosto coberto por ele: "Pintar faz aquilo que se pode fazer sem palavras - evocar tudo e não dizer nada, fazer um convite ao significado, sem se comprometer com nenhum significado em particular, oferecer uma pergunta em aberto, em vez de respostas" (SOLNIT, 2017, p. 88).

No ensaio intitulado "Avó aranha", Solnit problematiza a questão da influência, citando como exemplo os artistas, cujas influências apontadas geralmente são seus precursores homens. O mesmo ocorre na literatura, como já observado por Sandra Gilbert e Susan Gubar (1984) no clássico feminista The Madwoman in the Attic. No entanto, em culturas onde o apagamento das mulheres se dá desde a genealogia familiar, que privilegiam a patrilinhagem, assim como em outras esferas sociais em que o trabalho das mulheres é obliterado, considerar apenas a influência de predecessoras reconhecidas seria igualmente um equívoco. Como observa Solnit, "a coerência do patriarcado, da ancestralidade, da narrativa é feita por eliminação e exclusão" (2017, p. 89). Com isso, é importante valorizar a experiência, pois de acordo com a autora "Todo mundo é influenciado por essas coisas que precedem a educação, coisas que surgem do nada na vida cotidiana. Essas influências excluídas eu chamo de 'as avós'" (SOLNIT, 2017, p. 91).

Com base no que foi exposto, é possível constatar que apesar de não ser um texto teórico e acadêmico, o livro aborda questões relevantes da pauta feminista. $E$, ao fazer uso de uma linguagem bastante acessível, por vezes movida pelo texto literário de grandes escritoras como Virginia Woolf e Susan Sontag, que são referências para a autora, Rebecca Solnit consegue demonstrar, por meio do seu próprio texto, que a palavra é potência transformadora e que pode ser não apenas um instrumento para dar início às revoluções ainda necessárias em nosso mundo, mas também o combustível e a fonte de inspiração e esperança para seguir resistindo.

\section{Referências}

BIROLI, Flávia. "Autonomia, dominação e opressão". In.: BIROLI, Flávia; MIGUEL, Luis Felipe. Feminismo e política: uma introdução. São Paulo: Boitempo, 2014, p. 109-122.

GILBERT, Sandra; GUBAR, Susan. The Madwoman in the Attic: The Woman Writer and the Nineteenth Century Literary Imagination. New Haven and London: Yale University Press, 1984.

SOLNIT, Rebecca. Os homens explicam tudo para mim. Trad. de Isa Mara Lando. São Paulo: Editora Cultrix, 2017. 
[Recebida em 12/08/2017 e aprovada em 25/10/2017]

Paula Queiroz Dutra Universidade de Brasília, Brasília, DF, Brasil

Paula Queiroz Dutra (qpaulad@gmail.com) é tradutora, doutoranda em Literatura na Universidade de Brasília e mestra em Letras pela Universidade Federal da Bahia (2008). Integra o Grupo de Estudos em Literatura Brasileira Contemporânea (GELBC) da UnB. Tem interesse em literatura contemporânea, em especial pela temática da violência sob o viés dos estudos de gênero.

4 Revista Estudos Feministas, Florianópolis, 26(2): e52128 